\title{
Laboreal
}

Volume $15 \mathrm{~N}^{\circ} 1$ | 2019

Trabalho e cooperação

\section{Cooperação e relações de confiança : a construção da segurança e da saúde no trabalho de alto risco}

Cooperación y relaciones de confianza : la construcción de la seguridad y la salud en el trabajo de alto riesgo

Coopération et relations de confiance : la construction de la sécurité et de la santé dans le travail à haut risque

Cooperation and trust relationships: the construction of safety and health in high-risk work

\section{Marcelle La Guardia e Francisco Lima}

\section{(2) OpenEdition}

\section{Journals}

Edição electrónica

URL: http://journals.openedition.org/laboreal/1331

DOI: $10.4000 /$ laboreal.1331

ISSN: 1646-5237

\section{Editora}

Universidade do Porto

\section{Refêrencia eletrónica}

Marcelle La Guardia e Francisco Lima, « Cooperação e relações de confiança : a construção da segurança e da saúde no trabalho de alto risco », Laboreal [Online], Volume 15 N$^{\circ} 1$ | 2019, posto online no dia 01 julho 2019, consultado o 12 abril 2020. URL : http://journals.openedition.org/laboreal/1331 ; DOI : https://doi.org/10.4000/laboreal.1331

Este documento foi criado de forma automática no dia 12 abril 2020.

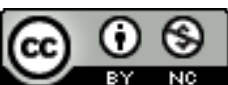

Laboreal está licenciado com uma Licença Creative Commons - Atribuição-NãoComercial 4.0 Internacional. 


\section{Cooperação e relações de confiança : a construção da segurança e da saúde no trabalho de alto risco}

Cooperación y relaciones de confianza : la construcción de la seguridad y la salud en el trabajo de alto riesgo

Coopération et relations de confiance : la construction de la sécurité et de la santé dans le travail à haut risque

Cooperation and trust relationships: the construction of safety and health in

high-risk work

\section{Marcelle La Guardia e Francisco Lima}

\section{NOTA DO EDITOR}

Manuscrito recebido em dezembro/2018

Aceite após peritagem abril/2019

\section{Introdução}

1 Quando decisões organizacionais afetam as práticas usuais de um coletivo, com dispensas, sanções, competições e promoções percebidas como injustificadas, pode-se assistir a uma rápida degradação da cooperação e da segurança (Daniellou, Simard \& Boissières, 2010). É por isso que transformações no trabalho devem ser feitas com cuidado, integrando ou pelo menos não perturbando as regulações individuais e coletivas que são invisíveis para aqueles que não estão próximos ao campo.

2 Os riscos ocupacionais, em parte, estão relacionados à impossibilidade de total padronização e antecipação das diversas circunstâncias que afetam a ação e suas interações em uma dada situação. É isso que torna indispensável o engajamento do 
trabalhador para controlar situações inesperadas, que podem trazer consequências para si, para o grupo e para a produção, apoiando-se nos saberes subjetivos e coletivos acumulados para dominar a complexidade no trabalho (Nouroudine, 2004 ; Schwartz \& Durrive, 2010 ; 2016).

3 Reconhecer a complexidade das situações de trabalho exige dos analistas do trabalho uma abordagem "intrínseca", que permita descrever como os problemas são tratados sob o ponto de vista dos próprios atores, opondo-se a uma abordagem "extrínseca" em que o observador realiza um recenseamento externo dos determinantes da ação para avaliar as dificuldades daquele(s) que age(m) (Daniellou \& Béguin, 2007; Theureau, 2014).

O presente artigo traz para discussão nesse dossiê sobre "Trabalho e Cooperação" uma controvérsia que teve origem em uma concessionária estatal do setor elétrico brasileiro e que divide opiniões a respeito da reorganização das equipes de eletricistas, questão esta que contrapôs gestores e engenheiros às equipes de operação e seus representantes sindicais. Os autores participaram, em 2014, de um "Acordo Pela Saúde e Segurança", estabelecido entre sindicato e empresa, que teve como foco o trabalho na Linha Viva (LV). Dentre as diversas questões debatidas, como a construção de um programa de redução de obesidade, a necessidade de veículos de apoio extras e os acidentes com trabalhadores terceirizados, a controvérsia sobre a redução do número de integrantes nas equipes motivou uma pesquisa mais aprofundada, desenvolvida como Mestrado (para uma apresentação resumida dos resultados do "Acordo", ver Castro \& Lima (2015)). Houve dificuldades de entrada no campo, levando cerca de um ano e meio para que a empresa autorizasse o acesso às equipes de LV. Por se tratar de uma questão já discutida na empresa e no âmbito do "Acordo", a adesão dos trabalhadores foi rápida, acelerando o processo da investigação e permitindo o aprofundamento das categorias de análise.

5 Este artigo inicia com uma breve explicação sobre o trabalho das equipes de LV e detalha dois elementos centrais na análise da problemática : o papel do encarregado e o do eletricista auxiliar. Após apresentar a atividade real desses atores, discutimos as categorias de análise resultantes do estudo: a interpenetração entre cooperação, confiança e a complexidade dessa atividade, como condição de gestão coletiva e individual dos riscos.

\section{As equipes de linha viva}

6 As exigências de alta qualidade na prestação de serviços impõem padrões normativos ao setor elétrico e impelem as concessionárias a se enquadrarem nos limites fixados por órgãos regulamentadores, sob pena de sofrerem multas. Essas imposições se dão por quatro motivos principais :

- a satisfação dos clientes, principalmente com o uso crescente de aparelhos e utensílios eletrônicos nas residências ;

- grandes empresas e comércios que dependem da energia para a produção e o funcionamento, inclusive serviços de saúde ;

- as regulamentações da ANEEL, que dispõem sobre as condições de regularidade, continuidade, eficiência, segurança e atualidade nos serviços do setor ; e

- aumento, nos últimos anos, dos "clientes com suporte à vida" que necessitam, em casa, de aparelhos elétricos que auxiliam na sobrevivência. 
7 Para se adequar a essas demandas, as empresas dispõem de tecnologias que permitem a estabilidade do sistema de distribuição de energia, como o uso de equipamentos na própria rede (por exemplo, religadores automáticos), a instalação de motogeradores, fixos ou móveis, e, também, a estratégia de manutenção em Linha Viva (LV). o trabalho em LV consiste na manutenção das redes aéreas de transmissão e distribuição de energia elétrica sem a interrupção do fornecimento. As operações de manutenção apresentadas aqui são realizadas no circuito energizado de Média Tensão (MT, 13,8 a $34,5 \mathrm{kV})$.

8 As equipes de LV da empresa estudada estão sendo impactadas pelo enxugamento do quadro próprio, devido à não reposição dos aposentados. As equipes são formadas por um encarregado fixo, na função de supervisor dos serviços, e pelos eletricistas executantes, que alternam funções de atuação na rede e apoio em solo. O número mínimo de integrantes nas equipes de LV previsto na norma da empresa era três, mas um estudo realizado em 1999 pela engenharia, setor de treinamento e representantes dos eletricistas concluiu pela viabilidade de realização dos serviços com dois integrantes, as chamadas "duplas". Um treinamento foi desenvolvido para aqueles que aceitaram trabalhar nesse novo formato e a manutenção com as duplas foi implementada. Após um acidente grave, ocorrido no mesmo ano, em uma equipe de quatro integrantes (quarteto), as duplas também foram criticadas pelos eletricistas e provisoriamente suspensas pela empresa.

9 Gerou-se, então, um acirrado debate entre, de um lado, gestores, engenheiros e técnicos da empresa (estes já foram eletricistas e atualmente fazem parte do Grupo Técnico responsável pela elaboração dos procedimentos de trabalho), e, do outro lado, os eletricistas e representantes sindicais. O primeiro grupo, o corpo técnico-gerencial, afirma ser "tecnicamente possível" a realização de serviços menos complexos com dois eletricistas, formato adotado por empresas de energia em outros países e estados do Brasil, como em São Paulo. Já o grupo operacional afirma que o trabalho em dupla aumenta os riscos de acidentes, além de intensificar a carga física e mental, com sérios comprometimentos à saúde.

10 Para trabalhar em duplas, o eletricista deve realizar um treinamento interno obrigatório, denominado "Condicionamento para Trabalho em Duplas". O objetivo do treinamento é preparar os profissionais para trabalhar em duplas com segurança, principalmente respeitando as normas da LV definidas pela empresa, como não desviar o olhar do serviço ao supervisionar um eletricista que está no poste ou na subestação.

11 Nas duplas, o encarregado passará a revezar entre as funções de execução e supervisão e o mesmo acontecerá com os eletricistas que antes ficavam exclusivos na execução. Se, durante a manhã, um eletricista executou e o outro foi o encarregado, na parte da tarde, haverá a inversão dessas funções. Nos trios, esse revezamento acontece somente entre os eletricistas executantes e o encarregado permanece na supervisão durante os dois períodos da jornada.

12 A norma para as duplas também considera a complexidade da tarefa a ser executada. Porém, ela é definida a priori: para serviços considerados menos complexos serão designadas as duplas e, em serviços considerados complexos, uma ou duas duplas se unem, recompondo equipes de quatro ou seis integrantes. Porém, se na norma esses métodos são capazes, em tese, de controlar efetivamente as lacunas deixadas ao se suspender o eletricista de apoio no solo e introduzir o revezamento de funções, o que 
acontecerá quando esta regra for aplicada nas situações concretas de trabalho, considerando aspectos individuais e coletivos do trabalho?

Como em debates dessa natureza raramente existem lados completamente certos ou errados, divergências funcionam como um motor para desenvolver o diálogo entre pontos de vista diferentes e fazer engrenar a construção de saberes sobre o trabalho, de modo a encontrar saídas seguras e eficazes para os problemas. A análise da atividade coletiva assumiu uma posição de mediação, ao recolocar a atividade real como objeto do debate. Nesse aspecto, encontramo-nos com tendências atuais que propõem colocar o "debate sobre a qualidade do trabalho" no centro da transformação da atividade (Clot \& Gollac, 2014), ou a instauração de "espaços de debate sobre o trabalho" permanentes na empresa (Rocha, Mollo \& Daniellou, 2015 ; Rocha, 2017) e o desenvolvimento de organizações reflexivas (Dejours, 2015).

\section{Metodologia}

14 Alguns elementos presentes nas situações analisadas poderiam ser objeto de quantificações, como, por exemplo, a frequência de tarefas simples ou complexas, um dos pontos centrais da controvérsia. No entanto, recorremos à metodologia qualitativa, que permite compreender melhor uma dada totalidade - neste caso o trabalho das equipes de LV - a partir de estudos empíricos. A metodologia utilizada foi a Análise Ergonômica do Trabalho (AET) (Guérin, Laville, Daniellou, Durrafourg \& Kerguelen, 2001), colocando o trabalho real no centro do estudo.

15 A amostragem foi construída no caminhar da investigação, como proposto por Flick (2009). Foram acompanhadas somente as equipes de LV de uma cidade de grande porte do estado, devido à maior acessibilidade a essas bases da empresa. Como há também uma divergência de pontos de vista entre os profissionais de cidades de pequeno/médio porte com os de cidades de grande porte, seria ideal que os primeiros também participassem, o que se tornou um dos limites para a generalização dos resultados.

16 Como na cidade estudada há dois centros de distribuição da empresa, decidiu-se acompanhar em campo uma equipe de cada: um trio e um quarteto. É importante ressaltar que outras estruturas foram observadas, mas em menor frequência. Foram realizadas entrevistas semiestruturadas com quatro eletricistas, cinco encarregados, quatro técnicos e com uma psicóloga da empresa. Essas entrevistas foram feitas paralelamente às análises do material das observações e das autoconfrontações, sendo fundamentais para aprofundar alguns dados colhidos e categorias que iam surgindo durante o processo.

17 O estudo teve um total de 112 horas de acompanhamento da jornada de trabalho e 64 horas de observação da atividade em diferentes dias da semana. Foram acompanhadas 22 ordens de serviços, tendo sido observados 14 tipos diferentes de serviços. Dessas 22, 3 foram recusadas em campo após a avaliação da equipe, por apresentarem risco para a segurança durante a sua execução. Serviços considerados simples e outros complexos foram observados, mas foi dada preferência aos serviços que as duplas poderiam executar. Foram observados, no total, quatro encarregados diferentes em campo, sendo dois com maior frequência. Houve um serviço executado com união de equipes : dois trios se uniram para executar um serviço. 
18 As entrevistas em autoconfrontação foram um importante recurso para acessar como o sujeito age, percebe e utiliza os meios disponíveis para alcançar seus objetivos em situações reais. Essa técnica pode ser simples (realizada com o próprio ator) ou cruzada (realizada com colegas da mesma função). Theureau (2014) defende a necessidade de se fazer inicialmente a autoconfrontação solicitando ao ator que comente, descreva ou narre sua atividade em um dado instante, utilizando traços objetivos colhidos durante a fase de observação. Para situar o ator no momento da ação, utilizaram-se duas câmeras : uma fixa, filmando todo o serviço com o deslocamento realizado pelos eletricistas no solo e o executante no poste, e outra filmando o ângulo de visão do encarregado (posicionada às suas costas), sendo segurada pela pesquisadora através de um suporte, durante todo o tempo do serviço. Foram filmadas seis execuções, mas, devido ao curto tempo disponível para fazer o aprofundamento necessário em cada uma, optou-se por realizar a autoconfrontação de quatro delas, consideradas mais frequentes, simples e executáveis pelas duplas, de acordo com a norma da empresa.

19 Foram realizadas duas reuniões de validação dos dados coletados, com duração de 50 minutos cada. A primeira foi realizada na etapa inicial de focalização com uma das equipes acompanhadas em campo, mostrando as categorias que emergiram das entrevistas e das observações iniciais. A segunda foi realizada com uma equipe que não foi acompanhada, testando a generalidade dos resultados.

\section{A atividade do encarregado nas equipes}

20 O encarregado é o responsável pela qualidade e eficiência da manutenção prestada, bem como pela segurança da equipe, principalmente dos executantes que estão realizando a intervenção com a rede energizada. Antes de iniciar a operação, ele se certifica das condições físicas e mentais de toda a equipe e auxilia a definir o melhor procedimento para a execução das tarefas, considerando a segurança, o menor esforço físico e o menor tempo.

21 Ao iniciar a operação com a subida da cesta aérea pelo executante, o encarregado fica dedicado exclusivamente à supervisão do serviço. A observação do trabalho permitiu registrar as mudanças de posição deste profissional, realizadas para ver todo o conjunto (instalações elétricas e o que o eletricista realiza), e as suas verbalizações ao detectar problemas, para se certificar de algo ou sugerir formas mais adequadas de realizar a operação.

22 Nas entrevistas, pôde-se encontrar uma primeira pista do que o encarregado de fato realiza : a antecipação das ações do executante em interação com os componentes do meio ambiente e das instalações elétricas. Essa antecipação permite visualizar situações potenciais de risco e evitar acidentes antes que determinado movimento do agente possa gerar um arco elétrico, como mostra o trecho da entrevista a seguir :

“Encarregado (E) : É uma visão global, por exemplo, você já tem que estar um passo à frente, o que pode acontecer nele executar aquele serviço, pode acontecer o quê? Pode fechar um curto ali na frente? Vai ter uma parte descoberta? Tem alguma coisa que tá caindo? Porque muitas vezes você está olhando aqui e olha pra um outro serviço. A partir do momento que já tá com uma certa experiência, você tá olhando ele trabalhando num ponto de serviço aqui, você tá olhando aqui, mas tá prestando atenção em outra coisa [lá na frente], já presta atenção já. (...) eu consigo ir além do que tá fazendo, consigo enxergar [grifo nosso]". 
Porém, somente com as autoconfrontações é que foi possível aprofundar e entender a atividade dos encarregados. As autoconfrontações foram realizadas com toda a equipe para aprofundamento técnico da situação e, posteriormente, eram conduzidas individualmente com os eletricistas e encarregados. Assim, identificou-se que "ir além" significa ser capaz de prever os próximos passos do executante: "Nós somos o batedor, né? Como se diz, eu vou na frente vendo o caminho". Estar "um passo à frente" exige o conhecimento não apenas de como se executa determinado serviço e o que as normas solicitam, mas, sobretudo, saber como aquele determinado eletricista opera, quais as limitações e potencialidades de seu corpo, seu ritmo, seus hábitos, suas regras e sua maneira de fazer. Para gerir os riscos que o executante está exposto, o encarregado realiza internamente as interações possíveis entre os componentes das instalações e as ações deste eletricista, o que permite interromper determinados movimentos ou comportamentos que possam ocasionar acidentes.

A diferença entre os estilos na execução também surgiu nas brincadeiras entre os integrantes, que revelavam seus diferentes jeitos de ser. Ainda que eles tenham realizado treinamentos para execução em determinada sequência, que também é acordada pelo coletivo ao pé do poste, cada eletricista a desenvolve em um ritmo próprio, que deve ser percebido pelo encarregado. Ao interrogar os encarregados se havia diferença também na forma de execução, todos afirmam que sim e dão exemplos de eletricistas com os quais é preciso ter atenção maior em determinados pontos. Para compreender esta habilidade perceptiva do encarregado, é necessário distinguir "gesto" de "movimento" ou, como faz a Norma Regulamentadora de Ergonomia, a NR-17, "ritmo" de "cadência": "A cadência tem um aspecto quantitativo, o ritmo qualitativo" (Ministério do Trabalho e Emprego [MTE], 2002, p. 54), em que a definição da postura em ergonomia, que integra a "atitude", dá um "sentido" ao movimento, tal como analisado por Berthoz (1997). Não foi possível descrever em profundidade como o encarregado gere essa diferença, possivelmente pelo nível de entrosamento das equipes, que tornou a gestão das diferenças tácitas e já incorporada pelo encarregado que acompanha esses eletricistas há vários anos. Porém, uma importante pista foi encontrada nas autoconfrontações com base nas observações realizadas.

Durante a troca de uma cruzeta (peça que sustenta os cabos da rede de MT), o executante inicia a etapa de retirar a cruzeta deteriorada do poste, quando o encarregado pede para que ele a deixe "deitar" e também alerta para o risco de a mão francesa tocar na Baixa Tensão (BT). Posteriormente, durante a autoconfrontação, o encarregado comenta :

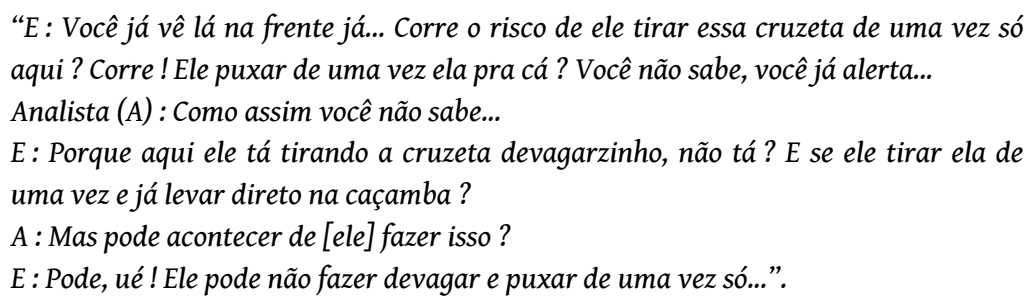

O risco verificado pelo encarregado foi de ocorrer uma rápida retirada da cruzeta e, como havia potenciais elétricos diferentes próximos àquele ponto, poderia esbarrar e fechar curto-circuito, gerando um acidente. Mas, por que esta forma rápida de execução aparece para o encarregado como uma possibilidade, se os eletricistas dizem que na LV a execução é sempre metódica e cuidadosa? Ao questionar se esta é a forma 
que este executante realiza a tarefa, o encarregado diz que alertaria qualquer um, porém, quando associamos esta situação à primeira entrevista realizada com este mesmo ator, ao questioná-lo sobre as diferenças de ritmos no trabalho, ele exemplifica que este executante, nesta situação de retirada da cruzeta, é o mais ágil da turma e que sempre redobra a atenção em suas execuções, embora seja muito experiente. Esse julgamento comparativo entre ritmos pessoais (estilos) explica como a diferença pode surgir para o encarregado.

27 Há uma atenção concentrada na operação para que o supervisor consiga antecipar os riscos. Em uma troca de cruzeta, quando o executante ia iniciar o isolamento pelo lado da rua desta estrutura, o encarregado o questiona : "Oh, [Paulo], esse centro da cruzeta tá bom mesmo ?". Paulo (os nomes são fictícios) diz que não está bom, mas é possível executar o serviço. Contudo, o que leva o encarregado a questionar, neste momento, sobre este ponto específico da estrutura? Lembrando que os lados são opostos : o executante está do lado da rua e o encarregado está olhando para o ponto que fica acoplado ao poste.

"E: Isso aqui [o eixo da cruzeta no poste] tá meio esquisito aqui, está feio. Aparentemente feio...

A: Por que você está olhando pra cá, se ele está mexendo aqui [ponta do lado da rua]?

E: Porque eu já vi aqui que aqui tá ruim. Já vi que isso aqui [local de fixação da cruzeta no poste] tá ruim. Ele tá mexendo, mas eu olho pros dois lados, olho para aqui [aponta para a ponta da cruzeta do lado da rua] e para aqui [aponta para a ponta da cruzeta próxima ao poste]! Então eu só alertei ele 'tá bom mesmo ?'. Porque ele tá mexendo, colocando cobertura, ele vai forçar ela.

A : Então no momento que ele vai pra colocar a cobertura aqui...

$E$ : Aí eu vi que ela tá feia mesmo aqui, só confirmei com ele 'oh, [Paulo], realmente tá bom ai mesmo?', porque, se tiver ruim aqui e colocar isolamento, ela cai ! Aí eu confio no quê ? No que ele fala, que ele tá lá perto ! [grifos nossos]".

Antes mesmo de o eletricista iniciar o isolamento, o encarregado antecipa o risco de a cruzeta cair, caso a madeira esteja apodrecida no ponto de fixação. Como não era possível ele avaliar, devido à distância ao solo, ele confirma com o executante e pede que ele verifique o estado daquela estrutura. É importante destacar que o que ele afirma ver é o ponto com aspecto "esquisito" e "feio". o que chama a sua atenção é esse aspecto determinado que está associado ao risco de a cruzeta desabar, pois, com uma fixação ruim, ao ser deslocada, a cruzeta de madeira pode quebrar e ocasionar um grave acidente. 0 encarregado, assim, atua como um "batedor" à frente do eletricista, fazendo conexões entre as ações do executante, os componentes das instalações e do meio ambiente e as possíveis consequências. Esta previsão que ele realiza, antes mesmo que a ação se inicie, é o que torna a gestão dos riscos compartilhada, não cabendo apenas ao eletricista em cima no poste, cuja atenção está voltada para sua segurança, mas, sobretudo, aos procedimentos técnicos específicos daquela tarefa.

Esses elementos somados levaram o encarregado ao questionamento, mas lembramos que tudo isso se passa em poucos segundos, pois o executante permanece em ação durante todo o tempo e as interações feitas mentalmente pelo encarregado devem levar a uma tomada de decisão rápida sobre o que falar e como falar. A atenção constante do encarregado é importante para conseguir intervir antes que um incidente ou acidente ocorra, como ressalta um eletricista : 
“(...) tipo assim, começou a pular alguma etapa, você ter o pensamento rápido e decisões rápidas, falar assim 'oh, parou!', 'ah, mas isso aqui tá bom pra mim', 'não, mas não tá bom, (...)'. Você ter esse pulso, porque, se você não tiver, você deixa ele fazer do jeito dele e às vezes não é o mais seguro, porque lá em cima é uma visão, aqui embaixo é outra [grifos nossos]" (eletricista de LV).

30 Além das visões serem diferentes, quando se está no alto do poste e quando se está no solo, os focos da atenção dos eletricistas são diferentes. Enquanto a supervisão embaixo é responsável por antecipar as possíveis interações que podem ocasionar acidentes, a execução está concentrada em realizar o serviço e os procedimentos técnicos. Isso não quer dizer que a gestão dos riscos também não ocorra pelo eletricista no poste, aliás, ela é inerente à própria atividade, mas eles focalizam riscos diferentes, ou os mesmos riscos de pontos de vista diferentes. As exigências cognitivas da execução são também elevadas, pois, às exigências técnicas específicas, somam-se a gestão dos riscos, o efeito psíquico da atividade perigosa e a carga física da tarefa realizada em ambiente aberto.

Os limites da regulação individual diante dos inúmeros elementos inesperados (variáveis ambientais, variáveis das instalações elétricas e variáveis subjetivas) fazem necessária a gestão compartilhada dos riscos neste trabalho. A cooperação na LV permite cercar as limitações individuais e torna-se uma condição para conseguir abarcar o máximo de situações potenciais de risco antes que elas ocorram, somando os olhares, as experiências, a atenção e os conhecimentos construídos por cada um no trabalho.

32 A atividade do encarregado está, assim, além da tarefa prescrita para a função de supervisão do serviço. Há um forte componente cognitivo relacionado ao conhecimento das instalações elétricas e de seus componentes em interação com as ações do eletricista; e um componente psíquico relacionado à responsabilidade pela segurança $\mathrm{e}$ a vida daquele que executa, bem como pelo posicionamento diante da empresa em caso de falhas ou problemas.

33 O aprendizado da supervisão de serviço se desenvolve já com o eletricista no solo atuando como auxiliar, vendo o encarregado se posicionar e intervir na execução do outro. $O$ desenvolvimento da competência de antecipação continua com o exercício de execução, criando um conhecimento compartilhado dos modos operatórios. Porém, o saber sobre o que falar e quando falar é desenvolvido com a prática cotidiana e, além dos conhecimentos dos modos operatórios, envolve um profundo conhecimento do outro no trabalho e das normas e regras internas a cada equipe.

A competência do encarregado se relaciona à redução das possibilidades que surgem concomitantemente à ação do executante, para que as intervenções sejam pertinentes e eficazes. Alguns fatores que tornam a atividade do encarregado complexa estão relacionados à gestão de múltiplas variáveis oriundas de diferentes fatores e à necessidade de tomar decisões rápidas, além de envolver um alto componente psíquico com a responsabilidade que carrega. É por isso que o tempo e a frequência para entrar em contato com as variabilidades são importantes na gestão dos riscos, pois permitem que as experiências acompanhem o desenvolvimento das estratégias necessárias para a promoção da saúde e da segurança, como a antecipação constante. $O$ conhecimento das regras explícitas desta atividade não é a única condição para o aprendizado desta gestão, posto que o saber incorporado é uma contínua evolução do corpo em movimento na ação. $O$ "saber como" (know-how) é diferente do "saber que" (know that), 
mesmo que estejam relacionados. Enquanto o último consiste no conhecimento das regras e fatos, o primeiro permanece em grande parte intraduzível em palavras, pois é na prática que o seu desenvolvimento acontece (Dreyfus \& Dreyfus, 2012).

O auxiliar contribui, então, para que o encarregado permaneça em sua função fixa ao longo do dia, mantendo o estado físico e mental necessário para conseguir realizar a antecipação que permite a gestão eficaz dos riscos, além de auxiliar o encarregado em seus próprios limites. É por isso que a inversão das funções ao longo do dia pode comprometer o estado considerado ideal para essa atividade, principalmente quando o supervisor da tarde executou algum serviço durante a manhã. O desgaste físico e mental da execução pode afetar a velocidade das tomadas de decisão, além de repercutir na sua atenção e percepção, essenciais para que os estímulos presentes no meio possam ser significados de acordo com as experiências passadas e, desta maneira, prever futuras situações de risco.

Para realizar a inversão, é preciso que as condições psicofisiológicas que permitem a antecipação eficaz estejam asseguradas no serviço da tarde. Como o desgaste físico da tarefa depende de elementos externos e internos ao trabalhador, os eletricistas pontuam a inversão como um problema a ser enfrentado nas duplas, pois não há garantias de que a capacidade de previsão das situações potenciais de risco, em tempo hábil para evitar acidentes, terá a mesma eficiência após uma manhã em que se executou.

37 A execução dos serviços possui um forte componente psíquico ligado à proximidade ao perigo, somado ao trabalho cognitivo de concentração e atenção constantes às variabilidades, aos procedimentos a serem realizados e às normas de segurança a serem obedecidas. $\mathrm{Na}$ intervenção no poste, o conteúdo físico da tarefa potencializa a demanda ao corpo, como o alto esforço dos membros superiores para sustentar os cabos, deslocar e instalar os equipamentos, tudo isso em posturas forçadas e, muitas vezes, sob forte calor.

A atividade de supervisão do serviço também pressupõe alta exigência do corpo, em especial das dimensões cognitivas e psíquicas demandadas na antecipação de situações potenciais de risco. A demanda física está principalmente relacionada à capacidade deste corpo em perceber, tanto por uma questão fisiológica (sensorial) quanto por um aprendizado do que os sinais do meio significam no "aqui e agora", ou seja, a figura sobre o fundo que emerge como um significante na tarefa, seja um potencial risco, uma melhoria para a qualidade ou eficiência.

A fenomenologia de Merleau-Ponty nos ajuda a entender como a discriminação perceptual passa a ser uma habilidade incorporada construída pelo mundo social e físico (Ribeiro, 2014). Perceber algo está sempre dentro de um contexto, pois é situado e histórico. A percepção torna-se personalizada com as experiências incorporadas que imprimem sentido aos estímulos do ambiente. Assim, para "estar um passo à frente", o encarregado também precisa estar um passo atrás, pois as experiências incorporadas permitem prever eventos futuros, e, também, no mesmo passo, pois são os estímulos do presente que dão a liga entre o que ele vivenciou e o que poderá vivenciar.

40 A estratégia encontrada para gerir as variabilidades intraindividuais que podem afetar a Saúde e Segurança no Trabalho (SST) é realizar uma ponderação coletiva, muitas vezes implícita e silenciosa, que integra duas dimensões : as condições do eletricista e de seus colegas e a demanda da própria tarefa. Escolhe-se sempre para a execução o eletricista que apresentar as condições físicas (estado de vigília, ritmo, equilíbrio, 
força), as condições emocionais (principalmente relacionadas a questões familiares), as condições mentais (atenção, memória, tomada de decisão rápida) e as competências específicas exigidas pelo trabalho, de acordo com o que a própria tarefa demanda. Por exemplo, em serviços mais complexos, o balanço é mais voltado para as condições mentais e emocionais, enquanto para serviços pesados é a condição física que irá se sobressair nesse equilíbrio.

41 A empresa acerta ao não tentar formalizar na norma todos esses parâmetros, objetivos e subjetivos, o que seria uma equação difícil e ineficaz para ajudar na decisão, e a delega ao encarregado que acompanha a execução. No entanto, ainda é necessário considerar as condições para que essa responsabilidade seja assumida de forma consequente. A gestão situada exige a adoção de métodos que deixem ao trabalhador margens de manobra para alocar as tarefas de acordo com as variabilidades, o que requer o revezamento entre os executantes. Ademais, o encarregado ser sempre fixo ao longo do dia permite manter o estado físico e mental julgado pelos pares como "essenciais" para a atividade.

42 As variabilidades ao longo do dia ou do mês e da semana são sempre absorvidas pela própria equipe, que se sente capaz de preencher as lacunas um do outro, tanto no que diz respeito às limitações físicas quanto mentais. Deste modo, mesmo que não haja impedimento técnico para realizar um dado trabalho, as flutuações cotidianas que ocorrem no corpo do trabalhador são geridas pela atividade coletiva e pelos vínculos profissionais e afetivos que ligam os integrantes da equipe. 0 eletricista auxiliar, assim, atua no revezamento com o eletricista executante e também coopera na supervisão sempre ativa do seu colega de trabalho, posto que tais variabilidades estão igualmente presentes com o encarregado.

O número de integrantes na equipe, portanto, não deve ser definido apenas pela visível e estável divisão de tarefas, mas, sobretudo, pela interdependência que acontece nas atividades do coletivo, que permitem que a gestão silenciosa e eficaz dos riscos aconteça também por mecanismos criados para gerir as variabilidades individuais cotidianas, muitas vezes ocultadas pelas normas prescritas pela organização.

\section{O papel do eletricista auxiliar : as regulações da equipe}

44 A tarefa prescrita ao eletricista de apoio no solo é : preparação do material necessário, carregamento da caçamba e movimentação de cargas, mesmo no decorrer da operação, permitindo que o encarregado não desvie o seu olhar do executante. No projeto das duplas, sem esse papel do eletricista de apoio na equipe, a preparação do material deve ser adiantada e, caso o executante necessite de algum carregamento durante o serviço, ele deve se afastar da rede para que o encarregado possa preparar e entregar o material.

Embora isto seja o formalmente esperado do eletricista auxiliar, a alocação de tarefas é sempre situada e acordada implícita ou explicitamente pela equipe, pois a sua divisão no campo, para além das normas e regras da empresa, é o que consolida uma interação funcional entre os eletricistas. 0 eletricista de apoio, para gerir a distância entre o que foi prescrito pela organização e o que é demandado pela situação concreta do trabalho e pelos seus colegas de equipe, também mobiliza outras competências intersubjetivas. 


\subsection{Os olhares vigilantes no trabalho da LV} requeridos na supervisão estiveram presentes como uma possível lacuna ao se introduzir as duplas, pois haveria apenas "um olhar" no solo. Eles afirmam que é mais arriscado dessa forma e que, dependendo do lado onde se está, pode não ser possível visualizar situações específicas de risco. Ter diferentes ângulos na supervisão significa que os eletricistas no solo se posicionam em diferentes locais de modo que seja possível cercar os "pontos cegos" um do outro. Trata-se de uma questão de limitação física humana, já que não é possível ter uma visão de $360^{\circ}$ durante todo o tempo. 0 encarregado cria, assim, estratégias que facilitam a supervisão, sendo as três principais observadas : desse trabalho, também por uma característica dos próprios equipamentos, que dificultam a visualização ao criar "pontos cegos", demandando ao encarregado que se desloque durante a execução, buscando sempre cercar tais limitações. Essas três estratégias permitem identificar elementos de risco previsíveis, que estão em jogo na situação daquele momento. Porém, o problema mais crítico é quando não é possível antecipar determinada situação, ou seja, aquela que foge do "previsível".

51 Foi observado que, na maior parte do tempo, o eletricista auxiliar atua ativamente na supervisão do executante em um ângulo diferente do encarregado, e a preparação do material ocorre, em grande parte, no início da tarefa. Em um acompanhamento realizado com um quarteto de $\mathrm{LV}$, a equipe estava na etapa final da troca de cruzeta em uma esquina e o encarregado se deslocou para o outro lado da rua, enquanto um dos auxiliares permaneceu em outro ângulo de visão. $O$ executante colocou a mão no suporte de ferramentas, que fica acoplada na caçamba, e, ao levantar o braço, o auxiliar disse : "O pino está aparecendo aí!". O executante interrompe a sua ação e pergunta "o quê ?" e o auxiliar volta a repetir "o pino está aparecendo aí !". O executante puxa a cobertura, cobre todo o pino e logo depois se aproxima daquele ponto para apertar a cruzeta.

A situação foi filmada do ângulo em que o encarregado estava e não era possível ver que o pino estava descoberto. Ao contrário, em sua posição, o pino parecia estar completamente isolado, pois a cobertura havia corrido justamente para o lado em que ele havia acabado de se posicionar. Segundo o auxiliar, ao ir pegar a chave no suporte de ferramentas, o próximo passo do executante seria apertar a cruzeta no poste e, ao abaixar o seu corpo para realizar isso, a cabeça ficaria próxima do pino. Se ela encostasse com o pino aberto, fecharia um curto (pino energizado e cruzeta aterrada) com dois potenciais diferentes, passando pelo eletricista e causando um grave acidente. 0 executante disse que, naquele momento, não havia percebido que a cobertura tinha corrido. Desse modo, do ângulo que o auxiliar estava, foi possível visualizar a falha no 
isolamento devido à movimentação da cobertura, o que não foi possível ser antecipado pelo encarregado, pois era justamente o ponto que ele havia acabado de olhar antes de mudar de posição e estava depois em seu ponto cego.

Segundo Assunção e Lima (2010), o afeto é visto como uma exigência em inúmeras profissões e possui ao menos dois determinantes extrínsecos: (i) as normas de gestão que procuram demonstrar ou encobrir tal sentimento e (ii) o próprio conteúdo da tarefa relacionado às interações entre os trabalhadores, os usuários e o contexto organizacional. Desse modo, a própria organização do trabalho é geradora das exigências afetivas, pois, para a atividade se concretizar, há um elevado nível de envolvimento emocional entre os atores. Como a gestão dos riscos na LV é coletiva e o suporte social revela-se fundamental, a construção dos vínculos afetivos no trabalho se forma sob a base também de regras, como o olhar constante do auxiliar no solo, não delegando apenas ao encarregado tal função. As normas tacitamente acordadas pelo grupo favorecem o desenvolvimento dos afetos (Vilela \& Assunção, 2007) e são, assim, causa e consequência do conteúdo emocional que oferece apoio ao coletivo frente às inconstâncias do meio. Esse elo afetivo é, sobretudo, profissional e liga os integrantes das equipes devido ao trabalho conjunto durante anos e, também, devido ao cuidado com o outro como regra da profissão.

\subsection{A regulação das variabilidades individuais}

54 As variabilidades intraindividuais dos integrantes da equipe podem ser mais sutis e exigem um maior conhecimento do outro no dia a dia para serem percebidas. Na Análise Preliminar de Risco (APR), o encarregado questiona a equipe se todos estão bem física e psicologicamente para verificar o estado de cada eletricista. No entanto, essa análise formal baseada no autorrelato não é suficiente, pois, embora o próprio executante se sinta apto a executar, o grupo percebe se ele está de fato em condições para o trabalho:

\section{“(...) porque muitas vezes a pessoa chega e não está bem... 'Ah, como é que você tá ?' 'Não, eu estou bem', mas realmente não tá, você percebe que não tá. (...) Você convive com a pessoa, você vê o jeito que ela chega, você sabe que ela não tá bem... " (encarregado de LV).}

Os estados emocional e físico são geridos pela equipe por estarem diretamente associados à cognição. A atenção e a memória são demandadas todo o tempo no trabalho e o estado de vigilância é outro componente fundamental para a gestão dos riscos. Assim, é preciso que o eletricista esteja bem para executar e também para supervisionar, o que faz com que a escolha do executante no dia esteja de acordo com os critérios estabelecidos pela equipe.

Se o encarregado achar que determinado integrante não deve subir, ele o pede para ficar como auxiliar no solo ou para que fique na base enquanto o restante da equipe sai para fazer o serviço. Em um dia de observação, enquanto a equipe ainda estava na base, um dos eletricistas ia sair para o campo. Porém, o encarregado solicita que ele fique na base, realizando a limpeza de um material, enquanto o trio sairia para o serviço. 0 técnico da base, vendo-o "desocupado", pede que ele auxilie uma equipe de outra base, mas o encarregado diz que necessita dessa limpeza para o dia seguinte e que este integrante não deve sair naquele dia. Posteriormente, o encarregado me diz que foi possível perceber, pelo andar do eletricista, que ele ainda não estava bem para o 
trabalho e até mesmo deixá-lo como auxiliar seria um sofrimento, devido à exposição ao sol e ao fato de ficar em pé por muito tempo, o que o fez se opor à decisão do técnico. Esse eletricista tinha retornado de uma licença médica há alguns dias, mas o encarregado julgou que ele ainda não tinha condições de executar a atividade. Essas microgestões cotidianas permitem que as equipes controlem os fatores internos a ela, ou seja, as diferenças subjetivas e as variabilidades inter e intraindividuais.

Apenas a convivência diária permite fazer esses julgamentos perceptivos, às vezes contrariando a avaliação do próprio eletricista que se julga apto a executar. Quando o encarregado diz, contra a resposta positiva do colega, que "realmente não tá, você percebe que não tá", ele não expressa os indícios objetivos desse julgamento. Isso porque os elementos envolvidos se manifestam inicialmente como diferenças em relação a um comportamento normal, como, usando a linguagem da fenomenologia de MerleauPonty, uma figura sobre um pano de fundo, tecido por anos de convivência: "Você convive com a pessoa, você vê o jeito que ela chega, você sabe que ela não tá bem...". Esse "jeito" diferente se manifesta porque colegas que convivem por anos se acostumam com o "jeito normal" do outro, sem que essas características sejam explicitadas. Por isso, as avaliações sobre as condições psicofisiológicas não se limitam ao que é dito, mas consideram, sobretudo, o que é percebido, ao que os corpos em relação falam e percebem sem dizer.

Além do estado mental, a condição física para o trabalho é igualmente importante, posto que ambas as dimensões, psicológica e física, jamais estão separadas : a fadiga física afeta a cognição e a sobrecarga mental repercute sobre os ritmos e o desempenho. Os eletricistas afirmam que algumas vezes acharam que o executante estava bem, mas, quando ele subiu e iniciou a execução, viram que o seu ritmo estava abaixo do que frequentemente realiza e pediram para que ele parasse a atividade e descesse da cesta para evitar um possível acidente, subindo o que estava como auxiliar.

59 Segundo a norma da empresa, o encarregado deve proceder ao revezamento quando suspeitar que há sinais de fadiga ou quando o eletricista solicitar a troca, antes mesmo de entrar em fadiga, ainda que esteja próximo ao final da tarefa. Nas duplas, segundo os técnicos, essa solicitação deve acontecer sempre antes que o cansaço comprometa a atividade, para que não comprometa a segurança. Todavia, a questão colocada pelos eletricistas é como identificar que se chegou ao limite da fadiga que afeta a capacidade de gerir os riscos, se várias vezes acharam que estavam bem até descer do caminhão :

\footnotetext{
"[Nas duplas] você tem que perceber antes de cansar, você não pode cansar pra perceber. Não tem jeito! Igual, plataforma, teve uma vez que nós estávamos em plataforma, aí o eletricista subiu (...), tava executando (...). Plataforma é no meio do mato, (...) é uma prancha com uma mão francesa isolada, você coloca o cinto e deixa o pé aqui assim, o seu pé não pode mexer, porque aqui tem um abismo e aqui tem um tripé, você fica paradinho [com as pernas], você mexe em cima [só com os braços] (...). Ele executou e aí: 'Cansei!'. [Eu disse :] 'Beleza, agora desce', [mas ele :] 'não tenho força pra descer!'. Porque você tem que desmontar o cadarço, tem que ter muita força pra passar pro poste... Aí colocamos a carretilha lá pra ele descer : método de resgate! Então, assim, na hora que ele sentiu que cansou, já tava exaurido. Já teve serviço, assim, que na hora que eu desci e sentei : que que é isso! Baixou a adrenalina, aí o seu sistema parassimpático tomou conta! Já teve situação que eu fiquei murchinho e só percebi na hora que desce" (eletricista de LV).
}

60 No caso narrado, a equipe não conseguiu identificar que a fadiga já estava presente, pois o eletricista permaneceu em seu ritmo. Trabalhar é, em certo sentido, realizar 
arbitragens em ação que exprimem uma polarização valorativa que mobiliza a postura, informa os gestos e orienta a abertura ou o fechamento diante do outro (Schwartz, 2014). Essa hierarquização, que se consolida a partir das interações sociais cotidianas e ao longo do tempo, infiltra-se em nosso corpo e deixa que os automatismos operem enquanto a atividade se orienta para superar as dificuldades que a tarefa coloca. $\mathrm{O}$ alto nível de atenção e concentração demandado na execução fez com que o eletricista colocasse em segundo plano o corpo fisiológico e suas regulações naturais.

61 Por isso a fadiga chega sem que seja percebida e não se pode deixar somente ao trabalhador individualmente a responsabilidade de autorregular sua carga de trabalho, pois a equipe exerce papel fundamental em campo para o gerenciamento das variabilidades, internas e externas, atuando como elemento mediador no curso da ação individual. Durrive e Schwartz (2008) recorrem ao termo "corpo-si" devido à dificuldade de nomear este sujeito que trabalha, mas que não é delimitado e definido ; ao contrário, suas bordas ultrapassam o espaço e o tempo presente e alcançam toda uma história vivida por si e, também, por outros. Há a dimensão física, a psíquica, a social, a institucional, a das normas e a dos valores neste corpo. É por isso que o "corposi" designa os diversos usos que se faz dele : por si e pelos outros. Trata-se, portanto, de uma constante dramática na atividade para fazer dialogar estas múltiplas instâncias internamente, que, quando confrontadas a situações como na descrita acima, realizam escolhas em detrimento de outras, que podem ser em prol da produção e não da segurança, mesmo da sua própria. Trabalhar pressupõe o estabelecimento de uma sinergia entre uma tríplice ancoragem : a biológica (com os limites e potencialidades do corpo dados no nascimento e no ciclo de vida); a histórica (com debates entre as normas que só adquirem sentido em um dado momento da história) ; e a singular (com a experiência de vida de cada pessoa com o "mundo de valores") (Schwartz, 2014).

A presença do "corpo-si" no trabalho transgride as fronteiras entre o biológico e o histórico. Aliás, para Schwartz, esta entidade historiciza o suporte biológico, já que a singularidade e a historicidade de uma situação local requerem a onipresença de um si que é, fundamentalmente, também um corpo (Schwartz, 2014). Quando o eletricista narra o caso em que, apenas ao descer do caminhão, sentiu o cansaço de seu corpo, ele revela como a hierarquização ocorre na ação e de modo inconsciente, já incorporada. Sua história imprime marcas no corpo biológico das hierarquizações tecidas com os anos de experiência, mas que são revividas a cada situação do presente.

É aqui que o coletivo entra como um mediador importante nesse uso de si por si, buscando criar normas para os limites do corpo. Uma das regras colocadas pela empresa é que o executante não fique mais de duas horas no poste e o encarregado providencie o revezamento ao concluir este tempo. No entanto, esta regra é negociada pela equipe, para mais ou para menos, o que torna fundamental este conhecimento do outro para identificar quando o eletricista não possui as condições adequadas para a tarefa. A equipe internaliza processos de seleção de informações pertinentes e é a condensação de uma história, profissional, social e local, que leva, sem um tempo de deliberação determinável, a um agir socialmente competente (Schwartz, 2014). Os julgamentos perceptivos sobre o estado do outro ficam "escondidos no corpo" devido a esse processo de internalização, o que o torna difícil de ser explicitado em regras formais. no solo, pôde-se adentrar um pouco mais na divisão da gestão dos riscos neste trabalho. 
Para Schwartz e Durrive (2010, 2016), a competência industriosa é aquela desenvolvida na atividade, sempre mergulhada em um contexto social. $\mathrm{Na} \mathrm{LV}$, o aprendizado das estratégias coletivas e individuais consolida a prevenção dos riscos que permeiam este trabalho, como os múltiplos olhares para suprir os "pontos cegos", a gestão das variabilidades inter e intraindividuais e a soma de experiências para transpor os obstáculos do campo. o funcionamento do coletivo, portanto, não é circunscrito a uma organização prescrita do trabalho, ainda mais em um contexto de trabalho perigoso em que a demanda pelo envolvimento emocional se torna uma característica intrínseca ao próprio conteúdo da tarefa.

\section{Cooperação, confiança e complexidade}

A cooperação pode ser um meio de reduzir a opacidade da tarefa e, portanto, sua complexidade relativa (Leplat, 2004), ao somar experiências para dar conta das imprevisibilidades das situações de trabalho. Porém, ao mesmo tempo, ela se torna mais um fator interno ao coletivo que aumenta a complexidade ao exigir o entrosamento e a confiança como importantes componentes da própria segurança no trabalho. Por isso, o relacionamento não pode ser ignorado pela organização ao se dividir ou unir equipes, pois, quando a hierarquia não conhece os fatores humanos envolvidos no campo, pode criar situações de trabalho que potencializam o risco ou aumentam a carga de trabalho.

É interessante notar que, nestas equipes, a percepção do estado mental e físico do outro está baseada em julgamentos tácitos desenvolvidos por meio de uma longa e contínua "co-elaboração" entre os pares. Por se tratar de uma exigência para a segurança na própria atividade, os eletricistas identificam no colega os critérios específicos que julgam essenciais para a execução e supervisão seguras. Perceber algo como arriscado ou seguro, como relevante ou irrelevante ou como similar ou diferente tem suas raízes na lida com o mundo natural e cultural em que vivemos, pois é a experiência que traz significados de acordo com as vivências individuais e sociais (Ribeiro, 2014). Nessa regulação, que é social, o corpo fisiológico é um elemento importante, mas não determinante.

o coletivo cria mecanismos de regulação para compensar os desequilíbrios e as descompensações internas : o funcionamento do "todo" é maior que a soma das partes, mas, quando uma das partes é afetada, o desempenho do "todo" é atingido. Canguilhem (2005) discute as diferenças entre as regulações internas a um organismo e na sociedade : enquanto o primeiro possui a capacidade espontânea de criar mecanismos regulatórios para equilibrar os desajustes internos, por exemplo, a termorregulação, a sociedade não possui esta "sabedoria orgânica". Ao contrário, ela cria e impõe meios para alcançar esse equilíbrio, que não é natural : "Não há sociedade sem regulação, não há sociedade sem regra, mas não há, na sociedade, autorregulação" (Canguilhem, 2005, p. 85).

Desse modo, quando os desequilíbrios no interior do coletivo são verificados, o saber social faz a mediação para tentar retomar a sua ordem. Nas equipes de LV, a regulação é realizada internamente às equipes, buscando equilibrar em campo as variabilidades dos integrantes, de maneira que as condições psicofisiológicas julgadas necessárias para o agir competente, individual e coletivo, estejam presentes. Como evidenciado, se a sabedoria social não intervém, os trabalhadores tendem inconscientemente a se 
sobrecarregar, assumindo tarefas em detrimento de sua saúde e segurança. Um dos argumentos que os eletricistas colocam como impossibilidade para a dupla é :

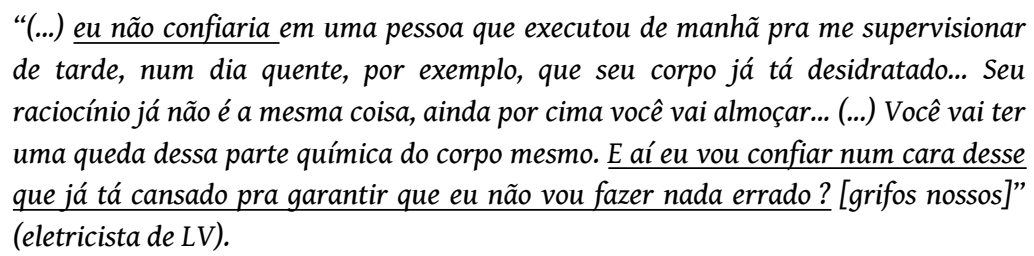
raciocínio já não é a mesma coisa, ainda por cima você vai almoçar... (...) Você vai ter uma queda dessa parte química do corpo mesmo. Eaí eu vou confiar num cara desse que já tá cansado pra garantir que eu não vou fazer nada errado? [grifos nossos]" (eletricista de LV).

A afirmação da "não confiança" apareceu em várias verbalizações dos eletricistas, não apenas com a possível inversão de tarefas com a dupla, mas também quando um encarregado não conhecido entra no lugar do encarregado que cotidianamente os acompanha. Se a segurança do executante no poste está intrinsecamente atrelada à atividade dos demais membros da equipe, como é possível confiar e conseguir operar sem o sentimento de estar amparado pelos colegas? É por isso que a confiança apareceu atrelada à cooperação nesta atividade e decidiu-se trazê-la como categoria para análise.

70 Luhmann (1988) apresenta a função da confiança associada à redução da complexidade. Em situações de risco ou incerteza, quando os interesses do agente não podem ser alcançados sem confiar no outro, a confiança surge como uma possibilidade de compartilhamento, o que propicia a construção de grupos solidários. Ela é, assim, a solução encontrada para problemas específicos de risco e requer um prévio engajamento das partes, em que os sujeitos associam à confiança expectativas e vantagens. É por isso que a confiança não está centrada apenas nas futuras ações, mas sim em como estas determinam as nossas ações presentes (Gambetta, 1988). No entanto, nem sempre o outro age de acordo com o que esperamos e a dúvida e a incerteza surgem como elementos que convivem com a confiança.

71 Para Gambetta (1988), confiar em alguém é mais o resultado do que uma condição para a cooperação. Desse modo, se o executante no poste sabe que não é possível realizar sozinho a gestão dos riscos presentes, ele conta com a equipe no solo para garantir a sua segurança, visto que se trata de uma atividade perigosa. Ele consegue dividir esta tarefa, pois confia nos integrantes e na cooperação estabelecida, ou seja, cria expectativas diante do comportamento do outro e, principalmente, de que as chances de falha são pequenas. É esta divisão do trabalho baseada na relação de confiança que permite diminuir a complexidade dessa atividade, pois compartilha-se com o outro aquilo que sozinho ele não seria capaz de conseguir com a mesma eficiência.

De maneira análoga, um dos critérios que a empresa impõe para as duplas é que os integrantes sejam colegas próximos no trabalho, sendo que "caberá à supervisão da empresa avaliar sempre a 'disposição afetiva' entre as partes quando da formação das duplas" (documento da empresa). Ao colocar a "disposição afetiva" como critério para as duplas, a organização permite que o sentimento de confiança esteja presente. No entanto, essa não é a única dimensão necessária, pois a base cognitiva é formada pelas informações de que a supervisão não irá falhar e está intrinsecamente ligada às competências e à condição física e mental do encarregado. É por isso que, ao afirmar que não se confia no supervisor de serviço que executou durante a manhã, os eletricistas estão se apoiando nesta outra dimensão da confiança. Ela é também a base para que a divisão da gestão dos riscos ocorra de forma cooperativa, isto é, acredita-se que o outro é competente, mas não apresenta, naquele momento, as condições físicas e 
mentais necessárias para cuidar da "minha" própria segurança. A confiança não é um estado, mas um processo dinâmico.

Segundo Karsenty (2013), o que está no coração do Modelo da Produção Dinâmica da Confiança são os julgamentos de coerência entre as expectativas criadas pelo ator e a observação dos comportamentos do outro e os resultados efetivados, ou seja, é a distância entre o que se espera e o que se percebe da ação do parceiro e o resultado final, que forma o seu núcleo central. Como a confiança é construída e não algo imposto aos sujeitos da relação, serão nas experiências interpessoais que esses julgamentos vão ocorrendo e consolidando tal sentimento para reduzir os riscos percebidos e tornar os objetivos críveis. Ela se metamorfoseia de acordo com a coerência identificada no desempenho do outro e, no caso da LV, pode se alterar quando se vê no "jeito do outro" a fadiga acumulada ao longo de um dia.

A confiança não se baseia somente em tais julgamentos feitos individualmente, pois ela é fruto de uma relação de cooperação e, portanto, a interação é o seu aspecto elementar. A confiança estabelecida entre os integrantes das equipes de LV é recíproca e é por isso que o comportamento e as competências de todos tornam-se pontos a serem observados para fazer engrenar o motor da confiança. Desse modo, nas equipes já consolidadas observadas, percebe-se que os chamados "recursos diretos da confiança" (Karsenty, 2013, p. 34) constituem o principal apoio dos eletricistas para confiarem no outro. Trata-se dos aspectos relacionados à competência, que se traduzem, por exemplo, na atenção constante durante a execução e nas intervenções acertadamente realizadas pelo encarregado ao interromper movimentos que podem resultar em acidentes. Por outro lado, o encarregado confia no executante quando este age de acordo com o que foi planejado e executa as normas de segurança acordadas.

Desse modo, a coerência entre as expectativas e as ações dos demais integrantes permite que a confiança seja desenvolvida e preservada neste serviço. Contudo, a gestão da confiança nessa atividade é o que dá liga aos dois lados de uma mesma moeda. Ao mesmo tempo em que permite reduzir a complexidade da tarefa, ao propiciar a divisão da gestão dos riscos de modo eficaz, ela também constitui um elemento dessa complexidade ao demandar a sua própria gestão no interior da atividade, fazendo com que os comportamentos e, principalmente, as comunicações sejam oriundas de um aprendizado que envolve a preservação desta relação. Essa complexidade pode ser quebrada pela divisão das equipes em dupla e não se reconstitui quando se juntam duas duplas para formar um quarteto. A soma dois mais dois acaba sendo, neste caso, menor que quatro $(2+2<4)$.

Um eletricista, ao relatar que, algumas vezes, assume como encarregado de outra equipe, diz que, nessas ocasiões, termina a jornada de trabalho exausto, sendo o dia em que ele chega em casa mais cansado e sem ânimo para fazer outras atividades. A menor previsibilidade demanda mais atenção e trabalho mental da supervisão, o que aumenta a carga de trabalho desse profissional. Assim, por mais que o encarregado não tenha total certeza da ação do outro, pois a dúvida se o executante está atento a algum ponto é que o faz intervir para alertá-lo, o desconhecimento do outro aumenta a demanda mental no trabalho. Quanto maior a imprevisibilidade, maior é a exigência extra para a supervisão, uma vez que as dúvidas se ampliam e fazem com que as intervenções aumentem na tentativa de controlar o comportamento do outro tornando-o, pelo menos em parte, mais previsível. 
77 Moigne (2000, p. 220) diz que “será complexo o que certamente não é totalmente previsível e às vezes não localmente antecipável”. A trama tecida por ações, retroações, determinações e imprevistos, que formam uma conexão peculiar e local - e, em grande parte, foge da possibilidade de antecipação e da visibilidade do agente -, caracteriza a dimensão singular dos eventos. É nesse ponto que se destaca o caráter situacional da complexidade. É a dimensão do "aqui e agora" que torna a incerteza e a imprevisibilidade fortes características desse adjetivo "complexo", tomado aqui como um conceito ou noção de "complexidade". Porém, falar de complexidade vai além, implica em trazer para o centro da discussão a qualidade de associação, de codeterminação, de interação e de relação (Leplat, 2004), que constituem a base estrutural do seu sentido aplicado aos fenômenos.

78 A complexidade, para Perrow (1986), é associada às características do sistema. Ela surge da multiplicação de conexões, até então desconhecidas, à medida que as demais partes do sistema forem sendo atingidas por determinado fator, inicialmente de baixo potencial de gravidade. Como as unidades estão acopladas e intrinsecamente ligadas, podem surgir inesperadas ligações e falhas, expondo o sistema e o trabalhador a graves acidentes. Desse modo, o corpo técnico se vê diante da dificuldade de criar um procedimento padrão para esses sistemas : a ideia da cristalização de uma única "ação ótima" é questionada, pois a complexidade requer uma gestão caso a caso. Para Leplat (2004), seria um reducionismo centrar-se em uma definição restrita ao número de elementos ou unidades que compõem o fenômeno e à ligação entre eles. Há, então, uma diferença entre sistema complexo, que ressalta as características intrínsecas ao dispositivo tecnológico, e tarefa complexa, que enfatiza a inter-relação entre o sujeito, a atividade e o dispositivo.

79 Para abordar a complexidade é preciso entender a lógica do modelo para aquele que o opera, que atua sobre ele em determinado espaço e tempo, pois há sempre uma relação de codeterminação entre o agente e a tarefa. É por isso que Leplat (2004) convida a uma abordagem que esteja relacionada também ao agente, à dimensão cognitiva, aos meios que o trabalhador e seus pares dispõem para gerir as variabilidades e aos resultados que se espera alcançar. É o elo entre o ator e a tarefa que define o caráter interativo da complexidade.

80 É necessário, assim, "refletir sobre a complexidade do trabalho para quem prescreve e os efeitos desta representação para o sujeito que gerencia a complexidade de seu próprio trabalho" (Vasconcelos et al., 2008, p. 410), visto que a tarefa prescrita não formaliza essas interações imanentes ao próprio sistema e demais variabilidades. Desse modo, para Leplat $(2004$, p. 74$)$, “toda teoria de competência encontra seu eco na análise da complexidade, assim como toda concepção de complexidade encontra seu eco na teoria da competência". Como a complexidade está na interação entre o agente e a tarefa, a competência na regulação dos riscos é um elemento fundamental para a segurança e está relacionada tanto à experiência individual quanto às estratégias desenvolvidas pela equipe.

81 Ao falar de complexidade, portanto, Leplat revela sua face de interação e codeterminação, pois a competência do agente é um dos elementos dessa classificação. $\mathrm{Na}$ LV, a competência envolvida é, sobretudo, partilhada, pois a eficácia da ação do executante no poste depende da sincronia da divisão implícita da equipe e da cooperação para a gestão dos riscos. Cabe aos eletricistas a regulação em campo que coloca em tensão permanente as exigências do sistema e as capacidades 
psicofisiológicas do trabalhador. As estratégias criadas por eles traduzem a inteligência frente à instabilidade do meio para que se mantenha o processo dentro das normas de segurança e de qualidade esperadas.

A cooperação que se desenvolve exerce um papel estratégico, uma vez que a eficiência do coletivo é um todo irredutível à soma das partes e permite um desempenho superior ao absorver e assumir as falhas e limitações individuais, por um lado, e articular os talentos e as qualidades singulares, por outro (Dejours, 2012; Figueiredo \& Athayde, 2004). O trabalho coletivo emerge, então, como um elemento de confiabilidade da LV que permite a eficácia da regulação através de mecanismos como : a antecipação feita pela supervisão, o compartilhamento da gestão dos riscos, a tomada de decisão conjunta e o controle da equipe sobre os estados físico e mental dos eletricistas.

83 A interação entre os membros é, assim, funcional e situacional (Leplat, 1994), pois a divisão do trabalho é congruente com as demandas encontradas em campo, para além da prescrição formal realizada pela organização. O papel do coletivo na redução da complexidade no trabalho da LV é exigido pelo próprio conteúdo da tarefa, pois a gestão da segurança não teria o mesmo alcance se realizada apenas pelo executante.

A abordagem ascendente, que revela os saberes-fazer de prudência constituintes de uma cultura de segurança cultivada no interior do coletivo, permite relativizar a negatividade estrita do risco e coloca em foco o seu lado positivo, que mobiliza a criatividade humana frente às situações potencialmente perigosas, em grande parte aquelas residuais, criadas pelas tecnologias e organização do trabalho (Nouroudine, 2004). Cooperação, confiança e complexidade são, assim, os três pilares da discussão desenvolvida nesse artigo e estão entremeados nesta atividade coletiva que alcança confiabilidade através das estratégias criadas para equilibrar as normas prescritas e a realidade do campo.

\section{Considerações finais}

A controvérsia entre o corpo técnico-gerencial e as equipes operacionais tem como foco a afirmação de ser tecnicamente possível o trabalho em duplas na LV. Após as análises realizadas que explicitam as condições de cooperação e desenvolvimento da confiança nas equipes, essa discordância pode ser esclarecida e debatida em nível superior. Essa é a eficácia específica de colocar o trabalho real em debate. Resumidamente, o trabalho em dupla é tecnicamente possível de forma abstrata, mas pouco provável nas situações concretas. Essa impossibilidade objetiva considera razões de eficácia, de eficiência e de segurança.

Se, com as duplas, vierem o aumento das recusas ou a realização do trabalho em situações de exposição ao risco, sua eficácia, econômica e prática, não será alcançada. Criar-se-á, assim, uma pressão organizacional para que as duplas assumam situações limites como se fossem simples, o que pode comprometer as regulações desenvolvidas para executar a atividade com eficiência e segurança. A cooperação e a confiança mostraram ser centrais na gestão da complexidade no interior da atividade e, como elas são formadas por relações que se desenvolvem com anos de convivência, ao somar duas duplas para formar um quarteto, a confiança e a cooperação poderão não estar presentes. Isso mostra que a conta dois mais dois é, na verdade, menor que quatro $(2+2$ $<4$ ), quando consideramos as regulações desenvolvidas para dar conta da complexidade caso a caso na LV. A fragmentação do grupo pode fragilizar a gestão coletiva dos riscos 
no curso da atividade e é por isso que o estudo do trabalho coletivo em situações complexas se interessa pelos mecanismos regulatórios criados na ação.

Assim, vimos que as decisões gerenciais, que tentam ajustar a demanda de serviços aos efetivos atuais sem novas contratações, podem restringir as margens de manobra desenvolvidas até então pelas equipes e criar descompassos no trabalho em campo, perturbando os mecanismos de regulação coletiva. Para construir uma segurança no trabalho, para além das ações preventivas que visam à aplicação de conhecimentos técnico-científicos generalizados, é preciso incorporar o savoir-faire dos trabalhadores, integrando a dimensão microscópica das situações de trabalho com a sua singularidade.

\section{BIBLIOGRAFIA}

Assunção, A. A., \& Lima, F. P. A. (2010). Aproximações da ergonomia ao estudo das exigências afetivas das tarefas. In D. M. R. Glina \& L. E. Rocha (Orgs.), Saúde mental do trabalho : da teoria à prática (pp. 210-228). São Paulo : Roca.

Berthoz, A. (1997). Le sens du mouvement. Paris : Odile Jacob.

Canguilhem, G. (2005). Escritos sobre a Medicina. Rio de Janeiro : Forence Universitária.

Castro, M. G. L., \& Lima, F. P. A. (2015). A intervenção sindical como estratégia de promoção da segurança integrada : a experiência do Pacto pela Saúde e Segurança. In F. P. A. Lima, L. B. C. Rabelo \& M. G. L. Castro (Orgs.), Conectando saberes : dispositivos sociais de prevenção de acidentes $e$ doenças no trabalho (pp. 213-254). Belo Horizonte : Fabrefactum.

Clot, Y., \& Gollac, M. (2014). Le travail peut-il devenir supportable? Paris : Armand Colin.

Daniellou, F., \& Béguin, P. (2007). Metodologia da ação ergonômica : abordagem do trabalho real. In P. Falzon (Ed.), Ergonomia (pp. 281-301). São Paulo : Blucher.

Daniellou, F., Simard, M., \& Boissières, I. (2010). Fatores humanos e organizacionais da segurança industrial : um estado da arte. In R. Rocha, F. Lima \& F. Duarte (Trads.), Cadernos da Segurança Industrial (Número 2013-07). Toulouse : ICSI. Retirado em 31 de março, 2019, de http://www.icsieu.org.

Dejours, C. (2012). Trabalho vivo. Brasília : Paralelo 15.

Dejours, C. (2015). Le choix. Paris : Bayard.

Dreyfus, H., \& Dreyfus, S. (2012). Expertise intuitiva : para além do pensamento analítico. Belo Horizonte : Fabrefactum.

Durrive, L., \& Schwartz, Y. (2008). Glossário de ergologia. Laboreal, 4(1), 23-28. Retirado em 31 de março, 2019, de http://laboreal.up.pt/revista/artigo.php?id=48u56oTV6582234396587;63882 .

Figueiredo, M., \& Athayde, M. (2004). Coletivos de trabalho e componentes subjetivos da confiabilidade em sistemas sociotécnicos complexos : considerações a partir da situação de trabalho em mergulho profundo na Bacia de Campos/RJ. In M. Figueiredo, M. Athayde, J. Brito \& D. Alvarez (Orgs.), Labirintos do trabalho : interrogações e olhares sobre o trabalho vivo (pp. 241-275). Rio de Janeiro : DP\&A. 
Flick, U. (2009). Uma introdução à pesquisa qualitativa (3a ed.). Porto Alegre: Bookman.

Gambetta, D. (1988). Can we trust trust? In D. Gambetta (Ed.). Trust: making and breaking cooperative relations (pp. 213-238). New York: Blackwell.

Guérin, F., Laville, A., Daniellou, F., Durrafourg, J., \& Kerguelen, A. (2001). Compreender o trabalho para transformá-lo : a prática da ergonomia. São Paulo : Blucher.

Karsenty, L. (2013). Comment appréhender la confiance au travail ? In L. Karsenty (Coord.), La confiance au travail (pp. 13-51). Toulouse : Octarès.

Leplat, J. (1994). Collective activity in work: some lines of research. Le travail humain: a bilingual and multi-disciplinary journal in human factors, 57(3), 209-226. Retirado em 31 de março, 2019, de https://www.jstor.org/stable/40659853.

Leplat, J. (2004). Aspectos da complexidade em ergonomia. In F. Daniellou (Coord.), A ergonomia em busca de seus princípios : debates epistemológicos (pp. 57-78). São Paulo: Blucher.

Luhmann, N. (1988). Familiarity, confidence, trust: problems and alternatives. In D. Gambetta (Ed.), Trust: making and breaking cooperative relations (pp. 94-108). New York : Blackwell.

Ministério do Trabalho e Emprego. (2002). Manual de aplicação da Norma Regulamentadora no 17 (2a ed.). Brasília : MTE/SIT.

Moigne, J. L. (2000). Sobre a modelização da complexidade. In E. Morin \& J. L. Moigne. A inteligência da complexidade (pp. 215-247). São Paulo : Fundação Peirópolis.

Nouroudine, A. (2004). Risco e atividades humanas : acerca da possível positividade aí presente. In M. Figueiredo, M. Athayde, J. Brito \& D. Alvarez (Orgs.), Labirintos do trabalho : interrogações e olhares sobre o trabalho vivo (pp. 37-62). Rio de Janeiro : DP\&A.

Perrow, C. (1986). Complexidade, interligação, cognição e catástrofe. Análise \& Conjuntura, 1(3), 88-106.

Ribeiro, R. (2014). The role of experience in perception. Human Studies, 37(4), 559-581. https:// doi.org/10.1007/s10746-014-9318-0.

Rocha, R., Mollo, V., \& Daniellou, F. (2015). Work debate spaces: a tool for developing a participatory safety management. Applied Ergonomics, 46(A), 107-114. https://dx.doi.org/10.1016/ j.apergo.2014.07.012.

Rocha, R. (2017). Espaços de debate e poder de agir na construção da segurança das organizações. Laboreal, 13(1), 86-91. https://dx.doi.org/10.15667/laborealxiii0117rr.

Schwartz, Y. (2014). Motivações do conceito de corpo-si : corpo-si, atividade, experiência. Letras de Hoje, 49(3), 259-274. https://doi.org/10.15448/1984-7726.2014.3.19102

Schwartz, Y., \& Durrive, L. (2010). Trabalho e ergologia : conversas sobre a atividade humana (2a ed.). Niterói : Editora da UFF.

Schwartz, Y., \& Durrive, L. (2016). Trabalho e ergologia II : diálogos sobre a atividade humana (1a ed.). Belo Horizonte : Fabrefactum.

Theureau, J. (2014). O curso da ação : método elementar. Ensaio de antropologia enativa e ergonomia de concepção. Belo Horizonte : Fabrefactum.

Vasconcelos, R. C., Lima, F. P. A., Abreu, A. C. M. S., Silva, R. C. R., Camarotto, J. A., \& Murta, E. P. (2008). A estratégia de "redução" e a carga de trabalho dos coletores de lixo domiciliar de uma grande cidade : estudo de caso baseado na Análise Ergonômica do Trabalho. Revista Brasileira de Saúde Ocupacional, 33(117), 50-59. https://dx.doi.org/10.1590/S0303-76572008000100006 
Vilela, L. V. O., \& Assunção, A. A. (2007). Trabalho emocional : o caso dos teleatendentes de uma central de atendimento. Cadernos de Psicologia Social do Trabalho, 10(2), 81-93. Retirado em 31 de março, 2019, de http://pepsic.bvsalud.org/scielo.php?

script=sciarttext\&pid=S1516-37172007000200007\&lng=pt\&tlng=pt

\section{RESUMOS}

Em uma concessionária de energia, as equipes de manutenção em rede energizada são formadas por, no mínimo, três integrantes. Com a redução do quadro de eletricistas, um estudo realizado pela engenharia, setor de treinamento e eletricistas da empresa concluiu pela viabilidade da realização de serviços com dois integrantes. Esse grupo técnico concluiu que é "tecnicamente possível" realizar as atividades dessa forma. No entanto, outros eletricistas e os representantes sindicais afirmam que a execução das tarefas em duplas irá afetar a saúde e a segurança dos trabalhadores. A solução passou por uma pesquisa que colocou em debate o trabalho real. Olhar para a atividade e as relações intersubjetivas possibilitou - e este é o objeto deste artigo desvendar como a cooperação e a confiança são construídas no dia a dia e como elas são bases para a eficiência da gestão coletiva dos riscos em situações complexas.

En una concesionaria de energía, los equipos de mantenimiento en red energizada están formados, como mínimo, por tres integrantes. Con la reducción del cuadro de electricistas, un estudio realizado por la ingeniería, sector de entrenamiento y electricistas de la empresa concluyó que era viable la realización de servicios con dos integrantes. Este grupo técnico concluyó que es "técnicamente posible" realizar las actividades de esa forma. Sin embargo, otros electricistas y los representantes sindicales afirman que la ejecución de las tareas en equipos de dos afectará la salud y la seguridad de los trabajadores. La solución pasó por una investigación que puso en debate el trabajo real. La mirada hacia la actividad y las relaciones intersubjetivas permitió - y ese es el objeto de este artículo - desvelar cómo la cooperación y la confianza se construyen en el día a día y cómo son bases para la eficiencia de la gestión colectiva de los riesgos en situaciones complejas.

Au sein d'une entreprise d'exploitation d'énergie, les équipes de maintenance d'un réseau sous tension sont composées d'au moins trois membres. En tenant compte de la réduction du nombre d'électriciens, une étude menée par les ingénieurs du service de formation des électriciens de la société a conclu qu'il est possible de réduire les équipes à deux personnes, concluant qu'il est “techniquement possible» de réaliser les activités de cette manière. Cependant, d'autres électriciens et les représentants syndicaux affirment que travailler en binôme peut affecter la santé et la sécurité des travailleurs. La solution est passée par une recherche qui a mis en débat le travail réel. L'analyse de l'activité et des relations intersubjectives a permis - et c'est le sujet de cet article - de découvrir comment la coopération et la confiance se construisent au quotidien et comment elles constituent le fondement de l'efficacité de la gestion collective du risque dans des situations complexes.

In a power distribution company, the maintenance teams at an energized network are formed by three members at least. With the reduction of the number of electricians, a study made by the engineering sector, training sector and electricians concluded that two-person services are viable. This technical group concluded that it is "technically possible" to carry out the activities this way. However, other electricians and trade union representatives say that performing the tasks in pairs will affect the employee's health and safety. The solution went through a research that placed the real work in center of the debate. Looking at activity and the intersubjective relationships has been made it possible - and this is the purpose of this article - to uncover how 
cooperation and trust are built up on a day-to-day basis and how they are bases for the efficiency of collective risk management in complex situations.

\section{ÍNDICE}

Palabras claves: supervisión para salud y seguridad, organización del trabajo y sistemas sociotécnicos, complejidad de las tareas, cooperación, confianza

Keywords: supervision for health and safety, work organization and sociotechnical systems, tasks complexity, cooperation, trust

Mots-clés: supervision de santé et sécurité, organisation du travail et systèmes sociotechniques, tâches complexes, coopération, confiance

Palavras-chave: supervisão para saúde e segurança, organização do trabalho e sistemas sociotécnicos, complexidade das tarefas, cooperação, confiança

\section{AUTORES}

\section{MARCELLE LA GUARDIA}

Situated Consultoria e Pesquisa - Avenida Prudente de Morais, 621, Santo Antônio, CEP 30350-143, Belo Horizonte, MG, Brasil

marcelle.laguardia.lara@gmail.com

\section{FRANCISCO LIMA}

Universidade Federal de Minas Gerais - UFMG ; Av. Pres. Antônio Carlos, 6627, Pampulha, CEP 31270-901, Belo Horizonte, MG, Brasil

fpalima@ufmg.br 